\title{
PERANCANGAN BISNIS BERBASIS WEBSITE PADA USAHA HIJAB RAF COLLECTION SIDOARJO
}

\author{
Linati Khairina Syarofah*, Endang Chumaidiyah, Wawan Tripiawan \\ Program Studi Teknik Industri, Fakultas Rekayasa Industri, Universitas Telkom \\ Email: linati.khairina@gmail.com; endangcn@gmail.com; \\ wawantripiawan@telkomuniversity.ac.id
}

Artikel masuk : 12-08-2021

Artikel direvisi : 01-09-2021

Artikel diterima : 17-09-2021

*Penulis Korespondensi

\begin{abstract}
Abstrak -- RAF Collection merupakan usaha yang bergerak dibidang fashion muslim khususnya produk hijab, yang berlokasi di Kota Sidoarjo. Usaha ini mulai berjalan pada bulan Juni 2020 dan kegiatan pemasarannya masih melalui social media seperti Instagram dan WhatsApp. Berdasarkan hasil wawancara, owner ingin melakukan pengembangan usaha serta merancang website untuk membantu kegiatan pemasaran, penjualan, serta komunikasi kepada konsumennya. Penelitian ini dilakukan untuk mengetahui kelayakan dari rencana pengembangan usaha yang akan dilakukan berdasarkan aspek pasar, aspek teknis, aspek finansial. Data pasar diperoleh dari penyebaran kuesioner kepada responden wanita berusia 15 - 40 tahun di beberapa kota seperti Surabaya, Sidoarjo, Jakarta, Malang, Bandung, Tangerang, Semarang dan Yogyakarta. Hasil perhitungan analisis kelayakan didapatkan nilai NPV sebesar Rp 233.318.479, nilai Payback Period selama 1,9 tahun, dan untuk hasil IRR sebesar $44,7 \%$, nilai IRR > MARR yaitu 11,47\%. Bisnis RAF collection layak dikembangkan berdasarkan hasil analisa aspek tersebut.
\end{abstract}

Kata kunci: Analisis Kelayakan; IRR; NPV; Payback Period; Perancangan Website

Abstract -- RAF Collection is a business engaged in Muslim fashion, especially hijab products, located in Sidoarjo City. This business started running in June 2020, and its marketing activities are still through social media such as Instagram and WhatsApp. Based on the interview results, the owner wants to do business development and design a website to help marketing, sales, and communication activities to consumers. This research was conducted to determine the feasibility of the business development plan that will be carried out based on the market aspect, technical aspect, and financial aspect. Market data was obtained from distributing questionnaires to female respondents aged 15-40 years in several cities such as Surabaya, Sidoarjo, Jakarta, Malang, Bandung, Tangerang, Semarang and Yogyakarta. The results of the calculation of the feasibility analysis obtained the NPV value of Rp. 233,318,479, the value of the Payback Period for 1.9 years, and the IRR result of $44.7 \%$, the value of IRR $>$ MARR was $11.47 \%$. The RAF collection business deserves to be developed based on the analysis results of these aspects.

Keywords: Feasibility Analysis; IRR; NPV; Payback Period; Website Design

\section{PENDAHULUAN}

Penduduk Indonesia mayoritas memeluk agama Islam dan menduduki peringkat pertama dengan jumlah sebesar 256,820,000 jiwa (Kusnandar, 2019). Industri yang bergerak dalam sektor pakaian di daerah Jawa Timur mengalami peningkatan hingga $4,45 \%$ dari tahun sebelumnya (Kementerian Perindustrian Republik Indonesia, 2019) sehingga membuat usaha bidang fashion mulai bermunculan, dan salah satunya adalah usaha hijab RAF Collection ini.

RAF Collection merupakan usaha fashion muslim yang berlokasi di Kota Sidoarjo, dan baru berjalan pada bulan Juni 2020. Produk yang ditawarkan oleh RAF Collection merupakan produk hijab dan aksesoris perempuan, untuk produk hijab terdapat dua macam yaitu pashmina dan persegi. RAF Collection masih tergolong 
usaha baru sehingga penjualan yang dilakukan masih belum stabil dan tingkat peminatnya masih tergolong sedikit (Gambar 1).

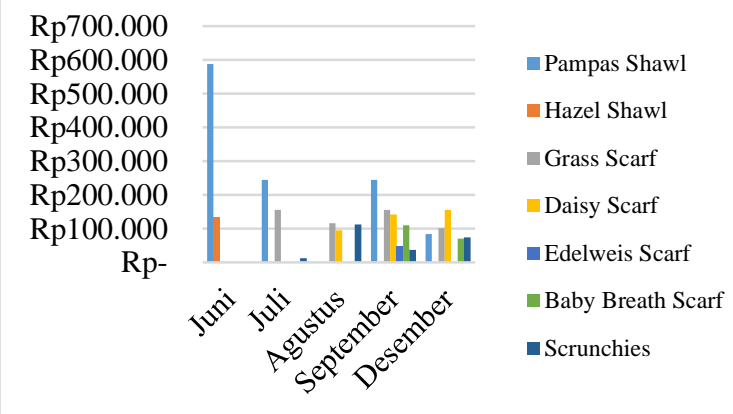

Gambar 1. Penjualan RAF Collection

RAF Collection melakukan kegiatan penjualannya dengan menggunakan media WhatsApp dan Instagram. Pemilik RAF Collection berencana mengembangkan usahanya secara online dengan menambahkan platform website untuk memasarkan produknya, serta menjual produk agar bisa memperluas pangsa pasar, dan meningkatkan pendapatan.

Penggunaan internet saat ini semakin meningkat, Berdasarkan survei yang dilakukan oleh Asosiasi Penyelenggara Internet Indonesia (APJII) pada tahun 2018 terkait jumlah pengguna internet di Indonesia mencapai 171,17 juta dari total populasi sebesar 264,14 juta orang pada saat itu. Peningkatan penggunaan internet ini dapat dimanfaatkan oleh pelaku usaha untuk menjalankan bisnis secara online. Fashion merupakan barang yang paling laris dibeli oleh konsumen secara online, dengan persentase sebesar 61\% (Pusparisa, 2019).

Fakta tersebut, membuat owner berkeinginan untuk mengembangkan usahanya secara online dengan membuat website untuk membantu penjualan dan pemasaran, agar bisa menjangkau pasar yang lebih luas dan juga meningkatkan profit. Alasan owner lebih memilih website karena website dapat dimanfaatkan untuk menyajikan informasi usaha lebih detail detail dibanding platform yang ada, membantu meningkatkan kredibilitas usaha di mata konsumennya, memasarkan produk yang dimiliki ke konsumen lebih luas lagi, memudahkan konsumen untuk mencari informasi secara akurat, dan pemilik usaha bisa merekam serta mencetak data penjualan secara otomatis dan terintegrasi dan juga dapat mengetahui basis data konsumen secara rinci yang nantinya bisa digunakan untuk menyusun strategi bisnis selanjutnya. Manfaat website tersebut juga telah disebutkan dalam penelitian Hernandhi et al. (2018) dan Nurfachmi et al. (2020).
Namun dalam melakukan pengembangan bisnis secara online perlu dilakukan pertimbangan secara matang agar tidak mengalami kegagalan. Berdasarkan data dari CB Insights mengatakan beberapa faktor penyebab startup mengalami kegagalan adalah tidak memperhitungkan kebutuhan pasar terlebih dahulu. Alasan ini memiliki persentase paling tinggi yaitu sebesar $42 \%$, dan urutan kedua dengan persentase sebesar $29 \%$ adalah biaya yang dikeluarkan tidak sesuai dengan perhitungan (CBInsight, 2019).

Oleh karena itu, pengembangan bisnis dan perancangan website pada usaha RAF Collection perlu dilakukan analisis kelayakan. Analisis kelayakan terdapat beberapa aspek yang akan digunakan, dimana meliputi aspek pasar, aspek teknis, aspek keuangan (Fauzi et al., 2019; Oktoyadi \& Wahyuni, 2019) yang memiliki tujuan untuk membantu mengetahui kelayakan pengembangan suatu usaha.

\section{METODE PENELITIAN}

Tahap awal penelitian dilakukan perumusan masalah, penentuan tujuan masalah, pencarian teori pendukung dari studi literatur dan studi lapangan. Rumusan masalah pada penelitian ini adalah menganalisis kelayakan dari usaha RAF Collection berdasarkan aspek pasar, aspek teknis dan aspek finansial. Kemudian dilakukan tahapan pengumpulan dan pengolahan data serta analisis kelayakan usaha.

\section{Studi Kelayakan}

Studi kelayakan merupakan suatu kajian yang berdasarkan dari beberapa aspek seperti aspek pasar, teknis, aspek, manajerial, sosial dan budaya, dan hukum dimana memiliki tujuan untuk mengetahui apakah suatu usaha layak atau tidak untuk dijalankan (Sulastri, 2016). Studi kelayakan menjadi salah satu studi yang mendalami tentang suatu bisnis yang akan dijalankan nantinya (Kasmir \& Jakfar, 2015).

\section{Aspek Pasar}

Asper pasar ini berkaitan dengan seberapa besar kemampuan perusahaan dan bagaimana strategi perusahaan untuk mencapai pasar (Zativita \& Chumaidiyah, 2019).

\section{Aspek Teknis}

Aspek teknis merupakan aspek yang berkaitan dengan teknis, lokasi, luas produksi, dan tata letak (layout). Aspek teknis dimanfaatkan untuk menilai kesiapan perusahaan menjalankan usahanya berdasarkan kegiatan produksi, layout ruangan, dan penggunaan mesin. Aspek teknis menghasilkan biaya investasi dan biaya operasional yang akan digunakan pada aspek keuangan (Nurazizah \& Chumaidiyah, 2020). 
Proses Bisnis merupakan proses yang menjelaskan suatu aktivitas atau pekerjaan secara terstruktur untuk menyelesaikan suatu masalah atau proses untuk menghasilkan suatu produk atau layanan demi mencapai tujuan tertentu (Widayanto, 2017).

\section{Aspek Finansial}

Aspek keuangan dianggap yang paling penting karena menggambarkan hal-hal yang berkaitan dengan keuntungan perusahaan. Aspek finansial merupakan salah satu aspek yang digunakan untuk menilai keuangan milik suatu usaha secara keseluruhan

\section{Analisis Kelayakan}

a. NPV

Net present value merupakan nilai bersih yang digunakan menganalisis kelayakan keuangan berdasarkan dari nilai arus kas bersih yang diterima, dan dibandingkan dengan nilai sekarang dari jumlah investasi yang telah dikeluarkan (Haris, 2019). Kriteria yang digunakan dalam melakukan perhitungan Net Present Value (NPV) untuk menentukan apakah menerima atau menolak proses investasi adalah jika NPV $\geq 0$ Investasi diterima dan NPV $<0$ Investasi ditolak (Chriswahyudi \& Darma, 2021)

\section{b. IRR}

IRR merupakan metode perhitungan suku bunga yang menyamakan nilai investasi saat ini dengan nilai kas bersih masa depan (Hanaa \& Chumaidiyah, 2020).

$I R R=i_{1}+\frac{N P V 1}{N P V 1-N P V 2} \times\left(i_{1}-i_{2}\right)$

Dimana $i_{1}=$ Tingkat Bunga pertama, $i_{2}=$ Tingkat Bunga kedua, NPV $1=$ NPV Positif dan NPV 2 = NPV Negatif. Persyaratan dalam hasil IRR adalah nilai IRR < MARR maka investasi yang dilakukan tidak layak, sedangkan nilai IRR > MARR, investasi layak dilaksanakan.

\section{c. MARR}

MARR (Minimum Attractive Rate of Return) adalah jumlah suku bunga minimum yang akan dipilih berdasarkan indikator yang telah ditetapkan (Atvidi et al., 2020).

\section{d. Payback Period}

Payback period merupakan metode yang digunakan untuk melakukan perhitungan investasi dalam jangka waktu tertentu, dan menunjukan adanya perubahan dalam penerimaan kas secara kumulatif dengan jumlah investasi dalam bentuk present value (Rahardja et al., 2019).

$$
P=\frac{\text { Investasi Bersih }}{\text { Kas Bersih Pertahun }} \times 1 \text { tahun }
$$

Kriteria penilaian payback period adalah jika PP lebih cepat dari umur investasi, maka usulan proyek atau investasi dapat dikatakan layak. Jika PP lebih lama dari umur investasi, maka usulan proyek atau investasi dikatakan tidak layak atau ditolak (Kholil \& Ramadhani, 2017).

\section{HASIL DAN PEMBAHASAN}

\section{Aspek Pasar}

Pada aspek pasar dilakukan penyebaran kuesioner terhadap 100 responden wanita yang berusia 15 - 49 tahun dari beberapa kota seperti Surabaya, Sidoarjo, Malang, Jakarta, Bandung, Semarang, Tangerang, dan Yogyakarta.

a. Pasar Potensial

Berdasarkan hasil responden yang berminat membeli produk RAF Collection sebanyak $67 \%$ kemudian dikalikan dengan total populasi dan dikalikan frekuensi pembelian sebanyak 2 , sehingga didapatkan sebanyak 10.900.064 pembelian.

b. Pasar Tersedia

Hasil responden yang bersedia membeli produk RAF Collection sebesar $57 \%$ kemudian dikalikan dengan pasar potensial sehingga didapatkan hasil pasar tersedia sebesar 6.230.378 pcs.

c. Pasar Sasaran

Pasar sasaran membidik sebesar $0,05 \%$ dari pasar tersedia sehingga diperoleh hasil pasar sasaran sebesar 3115, dan perkembangan demand 5 tahun ke depan disesuaikan dengan laju pertumbuhan penduduk sebesar 1,25\% (Tabel 1).

Tabel 1. Proyeksi Demand per Tahun (Pcs)

\begin{tabular}{lllll}
\hline $\mathbf{2 0 2 2}$ & $\mathbf{2 0 2 3}$ & $\mathbf{2 0 2 4}$ & $\mathbf{2 0 2 5}$ & $\mathbf{2 0 2 6}$ \\
\hline 3115 & 3154 & 3194 & 3233 & 3274 \\
\hline
\end{tabular}

\section{Aspek Teknis}

Aspek teknis akan menentukan proses bisnis, kebutuhan tenaga kerja, lokasi usaha, dan penentuan peralatan yang dibutuhkan. Pada usaha terdapat tiga proses yaitu proses pengadaan produk, pemasaran, dan melayani konsumen (Tabel 2).

Tabel 2. Waktu Proses Kegiatan RAF Collection

\begin{tabular}{lc}
\hline Kegiatan & Waktu (Menit) \\
\hline Pengadaan Produk & 160 \\
Pemasaran & 130 \\
Pelayanan Konsumen & 65 \\
\hline
\end{tabular}

Ketiga proses digunakan untuk menghitung kebutuhan tenaga kerja. RAF Collection beroperasi pada hari Senin - Jumat dari jam 08.00 
hingga jam 16.00. maka waktu kerja efektif perbulan didapatkan 8400 menit per bulan (Tabel 3)

Tabel 3. Waktu Kerja RAF Collection

\begin{tabular}{llll}
\hline $\begin{array}{l}\text { Jam } \\
\text { Kerja } \\
\text { (Jam) }\end{array}$ & 7 & $\begin{array}{l}\text { Hari } \\
\text { Kerja/Minggu }\end{array}$ & 5 \\
$\begin{array}{l}\text { Jam } \\
\text { Kerja } \\
\text { (Menit) }\end{array}$ & 420 & $\begin{array}{l}\text { Hari } \\
\text { Kerja/Bulan }\end{array}$ & 20 \\
\hline $\begin{array}{l}\text { Total waktu kerja efektif (menit) } \\
\text { (jam kerja/menit x hari kerja per bulan }\end{array}$ & 8400 \\
\hline
\end{tabular}

Perhitungan tenaga kerja didapatkan dari demand per tahun (Tabel 1) dibagi dengan 12 agar bisa mengetahui demand perbulannya. Dalam sehari RAF Collection melakukan proses mengecek sampai pemasangan label produk sebanyak 13 pcs. Waktu prosesnya didapatkan dari 160 menit dikalikan dengan 13 pcs diperoleh 2080 menit dan dibagi dengan waktu kerja efektif sehingga diperoleh kebutuhan tenaga kerja adalah 1 orang (Tabel 4).

Tabel 4. Perhitungan Tenaga Kerja Pengadaan Produk

\begin{tabular}{cccccc}
\hline & 2021 & 2022 & 2023 & 20242025 \\
\hline $\begin{array}{c}\text { Waktu Proses } \\
\text { (menit) }\end{array}$ & 2080 & 2080 & 2080 & 2080 & 2080 \\
$\begin{array}{c}\text { Waktu Kerja } \\
\text { Efektif (menit) }\end{array}$ & \multicolumn{4}{c}{8400} & \\
\hline $\begin{array}{c}\text { Jumah Tenaga } \\
\text { Kerja }\end{array}$ & 1 & 1 & 1 & 1 & 1 \\
\hline
\end{tabular}

Hasil perhitungan diketahui bahwa jumlah tenaga kerja yang didapatkan sebanyak 1 orang (Tabel 5). Untuk proses kegiatan pemasaran pekerja akan mengupdate konten sebanyak 2 kali dalam sebulan sehingga waktu proses pemasaran di kali 2 sehingga hasilnya 260 .

Tabel 5. Perhitungan Tenaga Kerja Pemasaran

\begin{tabular}{cccccc}
\hline & 2021 & 2022 & 2023 & 20242025 \\
\hline $\begin{array}{c}\text { Waktu Proses } \\
\text { (menit) } \\
\begin{array}{c}\text { Waktu Kerja } \\
\text { Efektif (menit) }\end{array}\end{array}$ & 260 & 260 & 260 & 260 & 260 \\
\hline $\begin{array}{c}\text { Jumah Tenaga } \\
\text { Kerja }\end{array}$ & 1 & 1 & 1 & 1 & 1 \\
\hline
\end{tabular}

Demand pertahun yang telah didapatkan sebelumnya (Tabel 1) dibagi dengan 12 untuk mengetahui demand perbulannya. Hasil demand per bulan dikalikan dengan waktu proses pelayanan konsumen yaitu 65 menit. Hasilnya dibagi dengan waktu kerja efektif per bulannya sehingga didapatkan 1 orang untuk pelayanan konsumen (Tabel 6).
Tabel 6. Perhitungan Tenaga Kerja Pelayanan Konsumen

\begin{tabular}{cccccc}
\hline & 2021 & 2022 & 2023 & 2024 & 2025 \\
\hline $\begin{array}{c}\text { Waktu Proses } \\
\text { (menit) }\end{array}$ & 16874 & 17085 & 17298 & 17515 & 17734 \\
$\begin{array}{c}\text { Waktu Kerja } \\
\text { Efektif (menit) }\end{array}$ & & & 8400 & & \\
\hline $\begin{array}{c}\text { Jumah Tenaga } \\
\text { Kerja }\end{array}$ & 1 & 1 & 1 & 1 & 1 \\
\hline
\end{tabular}

Jumlah peralatan seperti meja kursi disesuaikan dengan jumlah pekerja, dan untuk mesin jahit ditambahkan hanya 1 buah karena pekerja pada bagian pengadaan produk hanya ada 1 orang saja. Lokasi usaha RAF Collection akan digunakan untuk sebagai lokasi kantor usaha. Dimana lokasi kantor RAF Collection berada di Puri Surya Jaya dengan ukuran 5 x 14 m2. Lokasi berdasarkan keinginan owner dikarenakan dekat dengan lokasi supplier kerudungnya.

Usaha ini juga melakukan pengembangan usaha dengan melakukan pembuatan website, yang akan digunakan untuk melakukan kegiatan pemasaran, penjualan, serta media komunikasi untuk konsumen. Website akan dirancang agar bisa digunakan untuk dua aktor yaitu konsumen dan admin. Konsumen bisa melakukan pemesanan, melihat produk yang ditawarkan, mengkontak admin, terhubung dengan sosial media, dan melihat riwayat pesanan. Admin bisa melakukan konfirmasi pesanan, mengkonfirmasi pembayaran, menambahkan dan mengupdate produk. Untuk website RAF Collection dapat diakses melalui http://rafcollection.store/ (Gambar 2).

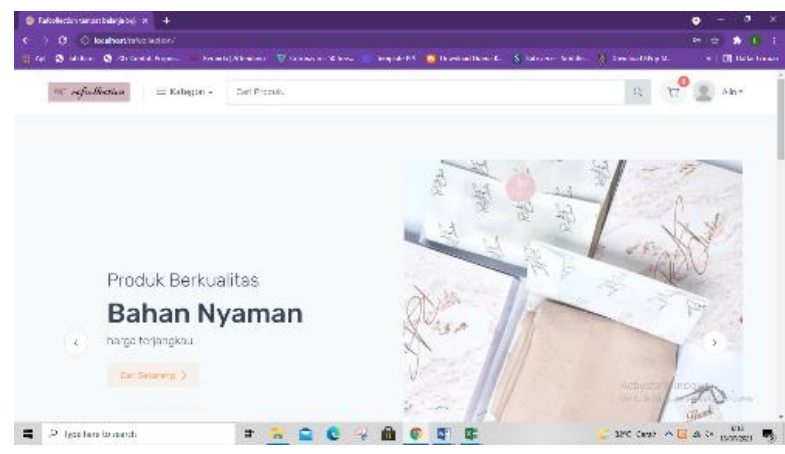

Gambar 2. User Interface Halaman Utama

\section{Aspek Finansial}

Pada aspek finansial menghasilkan perkiraan pendapatan, kebutuhan dana, laporan arus kas, NPV, IRR dan Payback Period. Penelitian ini bertujuan untuk melakukan pengembangan usaha serta perancangan website, maka penjualan dilakukan full secara online. Proyeksi pendapatan RAF Collection selama lima tahun kedepan (Gambar 3), setiap tahun mengalami peningkatan akibat peningkatan demand. 


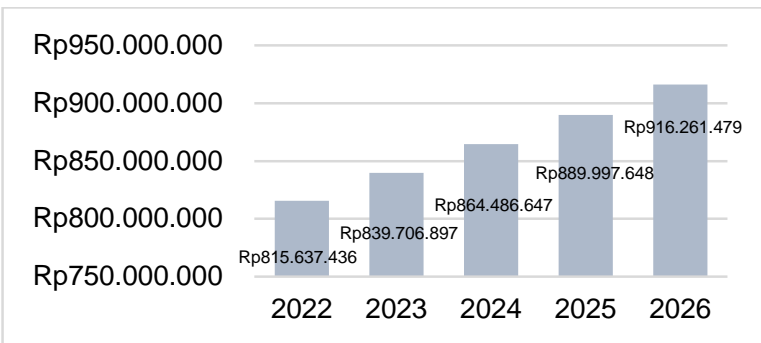

Gambar 3. Proyeksi Pendapatan

Kebutuhan dana merupakan suatu biaya yang harus dikeluarkan untuk biaya investasi perusahaan, dimana kebutuhan dana ini terdapat biaya investasi, seperti biaya peralatan dan pembuatan website dan biaya operasional perusahaan. Kebutuhan dana pada usaha RAF Collection ditunjukkan pada Tabel 7.

Tabel 7. Kebutuhan Dana

\begin{tabular}{ccr}
\hline \multicolumn{3}{c}{ Kebutuhan Dana } \\
\hline Fixed Investment & $\mathrm{Rp}$ & 40.588 .000 \\
Working Capital & $\mathrm{Rp}$ & 87.879 .480 \\
SIUP & $\mathrm{Rp}$ & 2.700 .000 \\
Trademark & $\mathrm{Rp}$ & 600.000 \\
\hline Total & $\mathrm{Rp} 131.767 .480$ \\
\hline
\end{tabular}

Laporan laba rugi untuk melihat kondisi keuangan dari usaha, apakah usaha tersebut akan mengalami kerugian atau akan mendapatkan keuntungan (Gambar 4). Laporan arus kas juga untuk melihat pemasukan dan pengeluaran yang dilakukan oleh perusahaan sehingga diketahui saldo kas akhir perusahaan (Gambar 5).

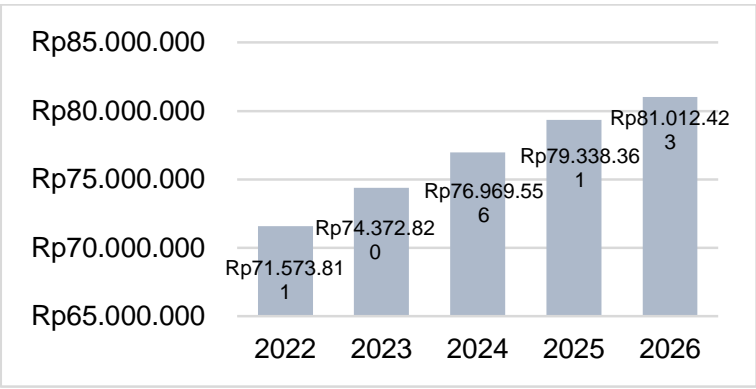

Gambar 4. Proyeksi EAT

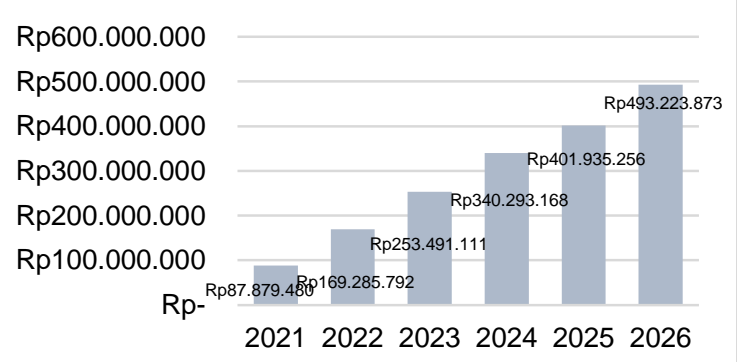

Gambar 5. Saldo Kas Akhir
Laporan neraca pada usaha RAF Collection menunjukan keseimbangan atau sama dengan nol, maka dapat dikatakan bahwa perhitungan keuangan pada usaha RAF Collection sudah benar. Penentuan kelayakan usaha menggunakan perhitungan NPV, IRR dan payback period. Hasil perhitungan menunjukkan nilai NPV sebesar Rp. 233.318.479, nilai IRR sebesar $44,7 \%$ dengan nilai MARR $11,47 \%$ dan untuk payback period sebesar 1,9 tahun sehingga usaha layak dikembangkan (Tabel 8).

Tabel 8. Perhitungan Analisis Kelayakan

\begin{tabular}{|c|c|c|}
\hline Interest Rate & & $11,47 \%$ \\
\hline NPV & $\mathrm{Rp}$ & 233.318 .479 \\
\hline Payback Periode & & 1,9 \\
\hline IRR & & $44,7 \%$ \\
\hline
\end{tabular}

\section{KESIMPULAN}

Berdasarkan hasil penelitian ditentukan yang pasar sasaran sebesar $0,05 \%$ dari total pasar tersedia, proyeksi demand sebesar 3115 pada tahun pertama dan untuk tahun selanjutnya meningkat sebesar 1,25\% berdasarkan dari laju penduduk Indonesia. Pada aspek teknis dilakukan perhitungan tenaga kerja untuk membantu menentukan jumlah peralatan yang dibutuhkan, serta menentukan lokasi usaha untuk menyewa bangunan untuk dijadikan kantor RAF Collection. Perancangan website nantinya akan membantu memudahkan pelanggan dalam melakukan kegiatan pemesanan, melacak status pesanan yang telah dilakukan, melihat informasi terkait social media dan sebagai media promosi yang dilakukan oleh RAF Collection. Hasil perhitungan keuangan selama lima tahun, didapatkan nilai NPV sebesar Rp 233.318.479, dengan nilai Payback Period selama 1,9 tahun, dan nilai IRR $44,7 \%$ dimana IRR > dari MARR (11,47\%). Hasil ini menyatakan bahwa kegiatan pengembangan usaha dan perancangan website RAF Collection layak untuk dijalankan.

\section{DAFTAR PUSTAKA}

Atvidi, A., Handoyo, H., Iriani, I., \& Purnamawati, E. (2020). Studi Kelayakan Investasi Pembelian Alat Transportasi Truk untuk Distribusi dengan Metode NPV (Net Present Value) dan MARR (Minimum Attractive Rate of Return) pada PT.XYZ. Tekmapro : Journal of Industrial Engineering and Management, 15(2), $37-48$. https://doi.org/10.33005/tekmapro.v15i2.162 CBInsight. (2019). The Top 20 Reasons Startups Fail. https://www.cbinsights.com/research/startup -failure-reasons-top/ 
Chriswahyudi, C., \& Darma, S. A. (2021). Analisa Kelayakan Investasi Alat Pengolahan Kerak Tembaga Di Pt. Tembaga Mulia Semanan. Jurnal PASTI, 15(1), 46-58. https://doi.org/10.22441/pasti.2021.v15i1.00 5

Fauzi, P. M., Chumaidiyah, E., \& Suryana, N. (2019). Analisis Kelayakan serta Perancangan Aplikasi Website pada Startup Digital Creative Fotografi Berdasarkan Aspek Pasar, Aspek Teknis, dan Aspek Finansial. Jurnal INTECH Teknik Industri Universitas Serang Raya, 5(2), 60-66. https://doi.org/10.30656/intech.v5i2.1589

Hanaa, R. W., \& Chumaidiyah, E. (2020). Measurement of Feasibility and Risk Level on Modern Embroidery Kebaya Boutique Establishment in Jakarta. IOP Conference Series: Materials Science and Engineering, 847(1), 12062. https://doi.org/10.1088/1757899x/847/1/012062

Haris, A. (2019). Studi Kelayakan Bisnis Tinjauan Teoritas Dan Praktik. Zifatama Jawara. https://books.google.co.id/books?id=IAACE AAAQBAJ

Hernandhi, D. T., Astuti, E. S., \& Priambada, S. (2018). Desain Sistem Informasi Pemasaran Berbasis Website Untuk Promosi (Studi Kasus Pada Kedai Ayam Geprak \& Sambal Bawang Malang). Jurnal Administrasi Bisnis, 55(1), $1-10$. http://administrasibisnis.studentjournal.ub.a c.id/index.php/jab/article/view/2235

Kasmir, \& Jakfar. (2015). Studi Kelayakan Bisnis: Edisi Revisi. Prenada Media. https://books.google.co.id/books?id=oQRB DwAAQBAJ

Kementerian Perindustrian Republik Indonesia. (2019). Lampaui 18 Persen, Industri Teksti dan Pakaian Tumbuh Paling Tinggi. https://kemenperin.go.id/artikel/20666

Kholil, M., \& Ramadhani, R. A. (2017). Analisis Kelayakan Investasi Workshop Pembuatan Spare Parts Mesin Industri dengan Menggunakan Metode Kriteria Investasi. Journal of Industrial Engineering and Management Systems, 8(2), 7-15. https://journal.ubm.ac.id/index.php/jiems/arti cle/view/120

Kusnandar, V. B. (2019). Jumlah Penduduk Muslim Indonesia. Katadata.Co.Id https://databoks.katadata.co.id/datapublish/ 2019/09/24/berapa-jumlah-pendudukmuslim-indonesia

Nurazizah, F., \& Chumaidiyah, E. (2020). Business Design and Feasibility of Puru
Kambera Muslim Fashion Offline Store Establishment. IOP Conference Series: Materials Science and Engineering, 1003(1), 12038. https://doi.org/10.1088/1757899x/1003/1/012038

Nurfachmi, S. R., Chumaidiyah, E., \& Prambudia, Y. (2020). Analisis Perancangan Bisnis Dan Website Pada Startup Bisnis Sepatu Inskres. EProceedings of Engineering, 7(3), 94239435.

https://openlibrarypublications.telkomuniver sity.ac.id/index.php/engineering/article/view/ 14162

Oktoyadi, O., \& Wahyuni, S. (2019). Kelayakan Pengembangan Bisnis E-Marketplace Perjalanan Ibadah Umrah Pada PT. Sarana Transwisata Teknologi. Jurnal Riset Perbankan Manajemen Dan Akuntansi, 3(2), 132-143. http://www.spsperbanas.ac.id/jrpma/index.php/jrpma/articl e/view/44

Pusparisa, Y. (2019). 5 Jenis Barang yang Paling Diburu Konsumen di E-Commerce Kepuasan Konsumen. Katadata.Co.ld.; Institut Teknologi Harapan Bangsa Bandung.

https:/databoks.katadata.co.id/datapublish/ 2019/11/11/5-sektor-barang-yang-palingdiburu-konsumen

Rahardja, A. Z., Chumaidiyah, E., \& Tripiawan, W. (2019). Feasibility Analysis on the Development of Steel Sheet Zinc Plated and Galvalum Production Factory PT. S Steel. IOP Conference Series: Materials Science and Engineering, 528(1), 12031. https://doi.org/10.1088/1757899x/528/1/012031

Sulastri, L. (2016). Studi Kelayakan Bisnis Untuk Wirausaha. LGM-LaGood's Publishing. http://digilib.uinsgd.ac.id/3141/

Widayanto, W. (2017). Analisis Proses Bisnis Usaha Mikro Kecil Menengah (Umkm) Konveksi Ryan Collection Di Kabupatan Kudus. Jurnal Administrasi Bisnis, 6(1), 2430. https://ejournal.undip.ac.id/index.php/janis/a rticle/view/16603

Zativita, F. I., \& Chumaidiyah, E. (2019). Feasibility analysis of Rumah Tempe Zanada establishment in Bandung using net present value, internal rate of return, and payback period. IOP Conference Series: Materials Science and Engineering, 505(1), $12007 . \quad$ https://doi.org/10.1088/1757899x/505/1/012007 